\title{
Accuracy of Panoramic Radiography for Detection of Periapical Endodontic Lesions
}

\author{
Tsv. Borisova-Papancheva' ${ }^{1}$, G. Papanchev ${ }^{2}$, T. Georgiev ${ }^{3}$, R. Andreeva ${ }^{4}$ \\ ${ }^{1}$ Department of Conservative Dentistry and Oral Pathology, FDM, MU-Varna \\ 2, 3Department of Oral and Maxillofacial Surgery, FDM, MU-Varna \\ ${ }^{4}$ Department of Pediatric Dentistry, FDM, MU-Varna
}

\begin{abstract}
The aim of this study was to evaluate the accuracy of panoramic radiography for detection of periapical endodontic lesions. 50 panoramic radiographs with endodontic treated teeth with periapical lesions were examined. They were processed by a computer program Adobe Photoshop CS5. The results showed that there was a statistically significant difference between mean values of the index $K$, measured in the angle of the mandible and the endolesion.
\end{abstract}

Keywords: panoramic radiograph, periapical endodontic lesions

\section{Materials and Methods}

A total of 50 panoramic radiographs from 50 patients from University Medico-dental centre, Faculty of Dental Medicine, University of Varna, Bulgaria were investigated. They were selected randomly. Planmeca ProMax ${ }^{\circledR 2 D}$ X-ray unit was used. It has a generator with resonance mode high frequency $80-150 \mathrm{kHz}$, focal spot size $0.5 \times 0.5 \mathrm{~mm}$ and constant magnification for panoramic radiographs - 1.2. The software for the images which was used is Planmeca Romexis®.

All the patients were registered by e-card, which includes patient's name and years as well as data from the panoramic radiograph in the software imaging Planmeca Romexis ${ }^{\circledR}$. The subject of retrospective analysis were digital radiographs of 50 patients with endodontic treated teeth with periapical lesions. The criteria used for inclusion in the study were: patients over 18 years old, coming for the first time in the Medico-dental centre, with a digital panoramic radiograph. The panoramic radiographs were processed by a computer program Adobe Photoshop CS5: 1. The panoramic radiograph was opened by Adobe Photoshop CS5 2. From the menu we chose Image » Mode » Grayscale » 8 bits/ Channel (fig.1). 3. Then select Move Tool (V) from the upper left corner of Adobe Photoshop CS5. 4. From the upper right corner of Adobe Photoshop CS5 we chose info and then recognized index $\mathrm{K}$, which gives us information about the intensity of black and white colour of the examined panoramic radiograph (fig.2). The index $\mathrm{K}$ was measured in two examined areas - 1. An area of healthy bone in the corner of the mandible. 2. An area of periapical lesion in an endodontic treated tooth.

The following exclusion criteria were attached: upper and lower third molars (wisdom teeth), patients under 18, patients over 69 , the totally toothless patients, teeth after endodontic surgery.

The results are recorded in tables and were subject to statistical analysis with specialized statistical analysis package STATISTICA.

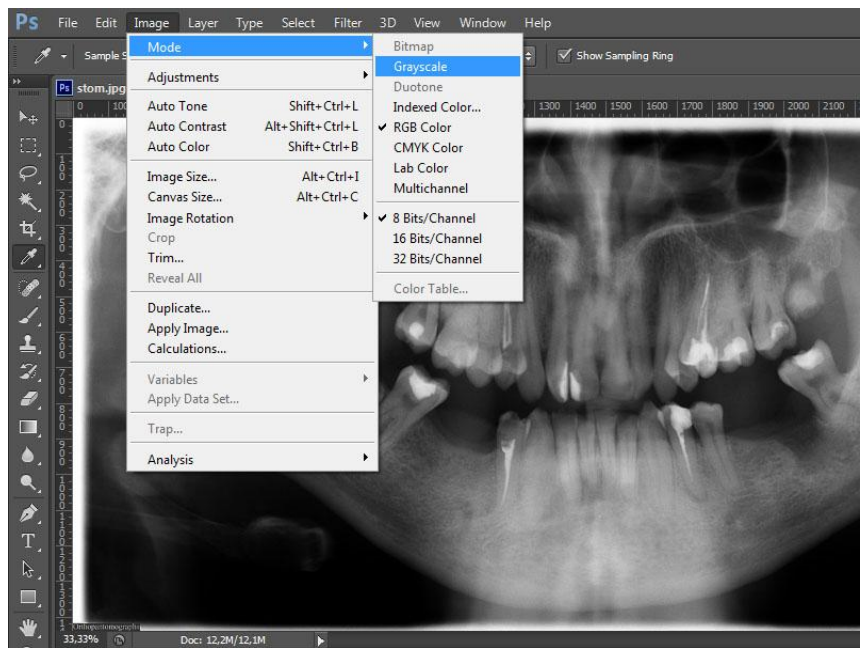

Figure 1: Analysis of a panoramic radiograph with Adobe Photoshop CS5 


\section{International Journal of Science and Research (IJSR) ISSN (Online): 2319-7064}

Index Copernicus Value (2013): 6.14 | Impact Factor (2015): 6.391

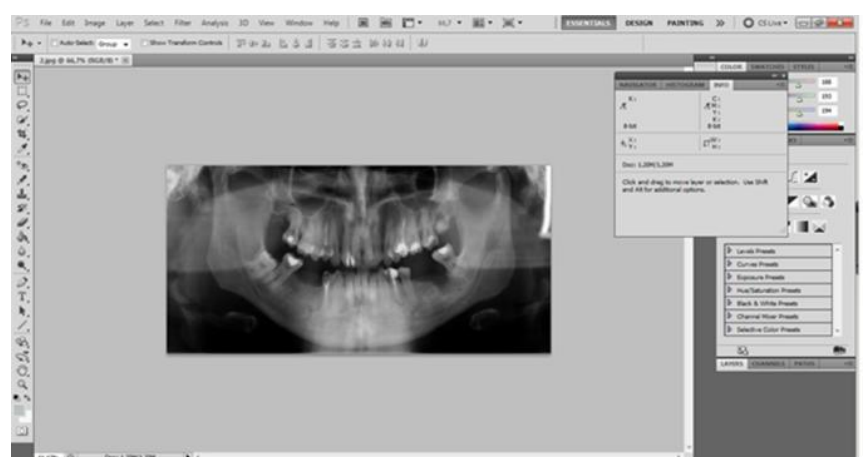

Figure 2: Analysis of a panoramic radiograph with Adobe Photoshop CS5

\section{Results}

The statistical analysis was conducted with specialized statistical analysis package STATISTICA (table 1).

Table 1: Results of comparing the presence of a statistically significant difference between the average values of the index $\mathrm{K}$, which was measured at the angle of the mandible and the endolesion

\begin{tabular}{|c|c|c|c|c|c|c|c|c|c|}
\hline & \multirow[b]{2}{*}{$\begin{array}{l}\mathrm{Me} \\
\text { an }\end{array}$} & \multirow[b]{2}{*}{\begin{tabular}{|l} 
Std. \\
Dv
\end{tabular}} & \multirow[b]{2}{*}{$\begin{array}{l}\text { Co } \\
\text { unt } \\
\end{array}$} & \multirow[b]{2}{*}{$\begin{array}{c}\text { Dif } \\
\text { f. }\end{array}$} & \multirow[b]{2}{*}{$\begin{array}{c}\text { Std.Dv } \\
\cdot- \\
\text { Diff. }\end{array}$} & \multirow[b]{2}{*}{$\mathrm{t}$} & \multirow[b]{2}{*}{ df } & $\begin{array}{c}\text { Confide } \\
\text { nce }\end{array}$ & \multirow[b]{2}{*}{$\begin{array}{c}\text { Confidenc } \\
\mathrm{e} \\
+95,000 \% \\
\end{array}$} \\
\hline & & & & & & & & $\begin{array}{c}-- \\
95,000 \\
\%\end{array}$ & \\
\hline $\begin{array}{l}\text { Angle of } \\
\text { the } \\
\text { mandible }\end{array}$ & $\begin{array}{l}51, \\
78\end{array}$ & $\begin{array}{l}40 \\
572\end{array}$ & & & & & & & \\
\hline $\begin{array}{c}\text { Endolesio } \\
\mathrm{n} \\
\end{array}$ & $\begin{array}{l}72 \\
82 \\
\end{array}$ & $\begin{array}{l}44, \\
387\end{array}$ & 50 & $\begin{array}{c}- \\
21 \\
04\end{array}$ & 47,378 & $\begin{array}{c}- \\
314, \\
013\end{array}$ & 49 & $\begin{array}{c}- \\
223,865\end{array}$ & $-196,935$ \\
\hline
\end{tabular}

From the statistical analysis was clear that $\mathrm{p}=0,00001<$ 0,05 , so there is a a statistically significant difference between the average values of the index $\mathrm{K}$, which was measured at the angle of the mandible and the endolesion.

The average value of the index $\mathrm{K}$ which was registered in an area of healthy bone at the angle of the mandible was e 51,78 (SD 4,05). The average value of the index $\mathrm{K}$ which was measured at the endolesion was 72,82 (SD 4, 43).

After analyzing the results of the retrospective study we described an index to assess the presence of a periapical endolesion by software processing of a digital panoramic radiograph (tabl.2).

Table 2: An index to assess the presence of a periapical endolesion

\begin{tabular}{|c|c|c|}
\hline $\begin{array}{c}\text { An index to assess the presence of a periapical } \\
\text { endolesion K }\end{array}$ & Score & Value \\
\hline $\begin{array}{c}\text { An index in an area of healthy bone at the angle } \\
\text { of the mandible }\end{array}$ & 1 & $41-57 \%$ \\
\hline $\begin{array}{c}\text { An index for normal periapical structures } \\
\text { (PAI1-2) }\end{array}$ & 2 & $58-64 \%$ \\
\hline $\begin{array}{c}\text { An index for presence of a periapical endolesion } \\
\text { (PAI 3-5) }\end{array}$ & 3 & $65-85 \%$ \\
\hline
\end{tabular}

\section{Discussion}

The most common procedures used to determine the periapical lesions are radiographic examinations $(1,2,3)$. The periapical index score (PAI) system relies on the comparison of periapical radiographs with a set of five radiographic images derived from Brynolf's histological-radiographic correlation study. It represents a healthy periapex (Score 1), the widening of the periodontal ligament (Score 2) and the progressive changes in mineral content of the periapical bone, the development of the periapical lesion (Score 3), the classic appearanceof apical periodontitis (Score 4) and its trend to expansion (Score 5) (4,5). Later periapical index' (PAI) scoring system has been modified and applied to epidemiological $(9,10)$ and clinical comparative studies of treatment outcome (11).

Tarcin et al. (6) evaluated observer variations and observer reproducibility in the interpretation of periapical health using the Strindberg system, the periapical index (PAI), and the probability index for radiologic assessment of periapical health. They concluded that The Strindberg system has lower intraobserver variation compared with the PAI and the probability index, whereas PAI has lower interobserver variation compared with the Strindberg system and the probability index.

Esposito et al. (7) presented a modified reproducible method to assess the CBCT-PAI. CBCT was used to evaluate a periapical bone lesion observed in the area of tooth number 13 before treatment and 2 years after treatment. modified CBCT-PAI was applied to both the examinations to measure the lesion. They concluded that the comparison of CBCTPAI with classic PAI showed the first method to be more precise.

Ridao-Sacie et al. compared the use of periapical radiographs and digital panoramic images displayed on monitor and glossy paper in the assessment of the periapical status of the teeth using the periapical index (PAI) (8). They found out that apical periodontitis was scored more often on paper than on screen, and more often on screen than in periapical radiographs.

\section{Conclusion}

Using software processing of digital panoramic radiographs in the diagnosis of periapical inflammatory changes of endodontic origin through a computer program Adobe Photoshop PS5 significant differences in the index $\mathrm{K}$ at the black and white colour of the studied areas were found. This gave us the opportunity to offer a new index for assessing the presence of a periapical lesion. This is another option for assessing the presence or absence of periapical lesions of endodontic origin.

\section{References}

[1] Torabinejad M, Corr R, Handysides R, Shabahang S Outcomes of nonsurgical retreatment and endodontic surgery: a systematic review.J Endod 2009;35: 930-937.

[2] Ng YL, Mann V, Rahbaran S, Lewsey J, Gulabivala K. Outcome of primary root canal treatment: systematic review of the literature - part 1. Effects of study characteristics on probability of success.Int Endod $\mathrm{J}$ 2007;40: 921-939.

\section{Volume 5 Issue 6, June 2016 www.ijsr.net}




\section{International Journal of Science and Research (IJSR) \\ ISSN (Online): 2319-7064}

Index Copernicus Value (2013): 6.14 | Impact Factor (2015): 6.391

[3] Ng YL, Mann V, Gulabivala K. Outcome of secondary root canal treatment: a systematic review of the literature. Int Endod J2008;41: 1026-1046

[4] Ørstavik D, Kerekes K, Eriksen HM. The periapical index: a scoring system for radiographic assessment of apical periodontitis.Endod Dent Traumatol1986;2: 20-24.

[5] Brynolf I. A histologic and roentgenologic study of the periapical region of human upper incisors.Odontol Revy 1967;18: 1-176.

[6] Tarcin B, Gumru B, Iriboz E, Turkaydin D, Ovecoglu H. Radiologic Assessment of Periapical Health: Comparison of 3 Different Index Systems. Journal Of Endodontics [serial online]. November 2015;41(11):1834-1838. Available from: Dentistry \& Oral Sciences Source, Ipswich, MA. Accessed June 14, 2016.

[7] Esposito, s; Cardaropoli, m; Cotti, e. A suggested technique for the application of the cone beam computed tomography periapical index. Dentomaxillofacial Radiology. 40, 8, 506-512, Dec. 2011. ISSN: 0250832X.

[8] Ridao-Sacie, C., Segura-Egea, J. J., Fernández-Palacín, A., Bullón-Fernández, P., \& Ríos-Santos, J. V. (2007). Radiological assessment of periapical status using the periapical index: comparison of periapical radiography and digital panoramic radiography. International Endodontic Journal, 40(6), 433-440

[9] Jimenez-Pinzon A, Segura-Egea JJ, Poyato-Ferrera M, Velasco Ortega E, Rios-Santos JV (2004) Prevalence of apical periodontitis and frequency of root filled teeth in an adult Spanish population. International Endodontic Journal 37,167-73.

[10] Kirkevang LL, Ørstavik D, Horsted-Bindslev P, Wenzel A(2000) Periapical status and quality of root fillings and coronal restorations in a Danish population. International Endodontic Journal 33 , 509-15.

[11] Kirkevang LL, Horsted-Bindslev P, Ørstavik D, Wenzel A (2001) Frequency and distribution of endodontically treated teeth and apical periodontitis in an urban Danish population. International Endodontic Journal 34 , 198-205

Volume 5 Issue 6, June 2016 www.ijsr.net 